\section{Kia ora koutou katoa: Australasian College of Sport and Exercise Physicians (ACSEP) warm up}

\author{
Hamish Robert Osborne (1) ,' Daniel Joseph Exeter ${ }^{2}$
}

Kia ora koutou katoa. Welcome to the Australasian College of Sport and Exercise Physicians (ACSEP) edition of the BJSM

In June/July 2020 the COVID-19 free land of Aotearoa New Zealand launched the first full return of professional basketball to the world. The national women's team, the Tall Ferns, played in front of a live audience in Auckland shortly before a small cluster of COVID-19 re-emerged and Auckland went again into lockdown. At the time of writing, New Zealand's 'team of 5 million' were socially isolating and getting used to wearing masks in public. While several parts of Australia are COVID-19 free, millions in Melbourne remain in lockdown. While some sports have managed to play in bubbles, others have had system failures and widespread viral infection involving whole teams.

As clinicians, COVID-19 has meant providing 'usual'medical care, to support athletes health, well-being and employment in isolation bubbles and then then in a heartbeat caring for whole teams with life threatening virus. Ultimately, there will be much musing over how we best supported athletes through a pandemic. Elimination again appears possible in New Zealand and athletes will again be able to return to full sport participation with large crowds watching. When New Zealand can do this on the international stage with our national teams is far from certain. This creates new challenges, caring for patients whose Olympic aspirations may still not come to fruition. Let's hope the great work in this issue by Lee Taylor et al (see page 1242) on cooling athletes in Tokyo does not prove in vain.

During the pandemic, online education has gained lots of attention but the Australasian College of Sport and Exercise Physicians has been working on a great sports medicine platform long before 'pandemic' was a household term. We are super excited, along with

${ }^{1}$ Medicine, University of Otago, Dunedin, New Zealand ${ }^{2}$ Department of General Practice and Primary Health Care, The University of Auckland, Auckland, Auckland, New Zealand

Correspondence to Dr Hamish Robert Osborne, Medicine, University of Otago, Dunedin, New Zealand; hamish.osborne@otago.ac.nz

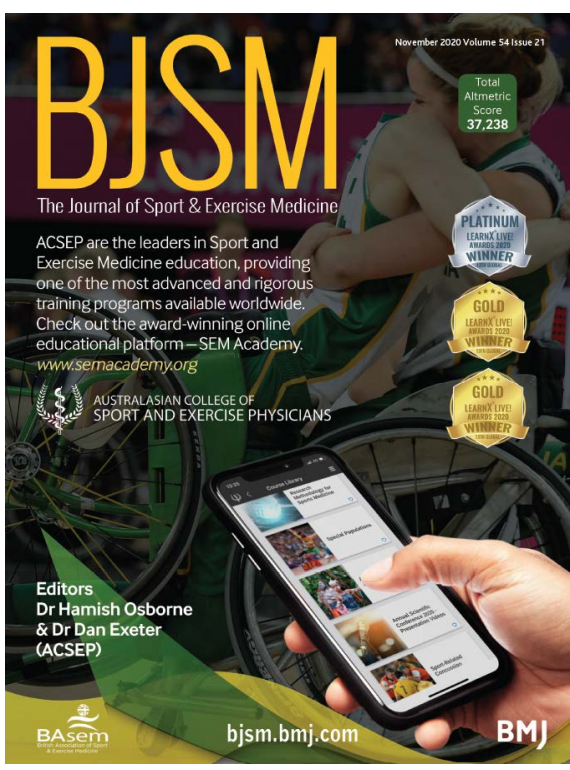

Figure 1 Celebrating SEMAcademy.org. The International award-winning online sport and exercise medicine education platform.

our creative partner White Leave Solutions (WhiteLeafSolutions.com) to have received top international awards for the SEMAcademy.org-leading the world with online sport and exercise medicine education. (Platinum award for Aboriginal Health and Cultural Safety and Gold for 'Pain Neurobiology') Follow the website for our upcoming 'Equipment in Para Sport' module (and thanks to Paralympics Australia for the cover image for this issue of BJSM (figure 1)).

We quietly remind our international readers that Australians have won 37 Olympic medals in rowing with New Zealander not far behind with 24, New Zealand's most successful Olympic sport. An Australian research team lead by ACSEP colleague Larissa Trease (see page 1288) followed 153 elite Australian rowers for two Olympiads identifying 270 injuries. Importantly, they uncovered a previously unidentified risk factor-the use of fixed ergometers. The study design did not allow them to conclude that this was a smoking gun but the study has alerted rowing clinicians to several risk factors to monitor carefully.
Relative Energy Deficiency in Sport (RED-S) should not be considered the domain of elite sport nor just women. However, the rib stress fractures reported by Trease et al (see page 1288) may represent RED-S in this cohort. In this edition, Doug Bentall (@dougbentall on Twitter), a self-described middle-aged cyclist elaborates on his experience (see page 1303) of being diagnosed with RED-S. Increasing body mass index (BMI) with age protects against all-cause mortality ${ }^{1}$ so RED-S may actually occur at quite high BMI as we get older. Therefore, RED-S is a problem that may well extend into old age. Villareal et $a l^{2}$ showed that aerobic exercise and dieting in those with sarcopenic obesity, while improving fitness, frailty and knee pain, leads to osteoporosis-is this RED-S in the elderly—should we be thinking about RED-E? Sweden's Gunilla Journath et al (see page 1294) report their amazing longitudinal study on exercise intervention over 22 years. It demonstrates very large changes in cardiovascular outcomes and, although outside the scope of this BJSM publication, likely many other health improvements.

Non-specific low back pain has seen so many treatments fall by the evidence wayside in the last two decades - acetaminophen, non-steroidal anti-inflammatory drugs, gabapentin, passive therapy interventions, injections and surgery. This contrasts with a resurgence in exercise therapy. Two meta analyses in this edition by Jill Hayden et al (see page 1277) and Postdoctoral fellow Patrick Owen et al (see page 1279) help to unravel some key issues with exercise interventions for chronic low back pain. Perhaps we should also consider paying patients to do their rehab? It seems to work for exercise prescription to improve other health outcomes as shown by Marc Mitchell et al (see page 1259). 'Safe' language also has a growing evidence base-Ivan Lin et al (see page 1240) contend that may be even more important than our physical interventions.

Importantly, we recognise the Wurundjeri people as the Traditional Owners of the land on which the national office of the ACSEP stands. We pay our respect to Aboriginal and Torres Strait Islander cultures; and to elders past and present. In Aotearoa New Zealand, the ACSEP acknowledge Māori as tangata whenua and respect the importance of working in partnership with iwi, hapū and whānau. In both countries, we must strive to reduce the health inequities experienced by our Indigenous populations.

Take care of each other and be kind. Nga mihi 


\section{Warm up}

Twitter Hamish Robert Osborne @Hamish_Osborne

Contributors HRO and DJE are the authors.

Funding The authors have not declared a specific grant for this research from any funding agency in the public, commercial or not-for-profit sectors.

Competing interests None declared.

Patient consent for publication Not required.

Provenance and peer review Commissioned; internally peer reviewed. (c) Author(s) (or their employer(s)) 2020. No commercial re-use. See rights and permissions. Published by BMJ.

\section{(A) Check for updates}

To cite Osborne HR, Exeter DJ. Br I Sports Med 2020;54:1237-1238.

Accepted 28 September 2020

Br J Sports Med 2020;54:1237-1238. doi:10.1136/bjsports-2020-103491
ORCID iD

Hamish Robert Osborne http://orcid.org/0000-00024265-4833

\section{REFERENCES}

1 Childers DK, Allison DB. The 'obesity paradox': a parsimonious explanation for relations among obesity, mortality rate and aging? Int J Obes 2010;34:1231-8.

2 Villareal DT, Chode S, Parimi N, et al. Weight loss, exercise, or both and physical function in obese older adults. N Engl J Med 2011;364:1218-29. 